\title{
BMJ Open Knowledge, attitude and practice of physical activity among patients with diabetes in Kilimanjaro region, Northern Tanzania: a descriptive cross- sectional study
}

\author{
Julius Lucas Mwimo (D) , ${ }^{1}$ Suzana Somoka, ${ }^{1}$ Beatrice J Leyaro (D) , \\ Caroline Amour, ${ }^{2}$ Experansa Mao, ${ }^{1}$ Innocent B Mboya (i) 1,2,3
}

To cite: Mwimo JL, Somoka S, Leyaro BJ, et al. Knowledge, attitude and practice of physical activity among patients with diabetes in Kilimanjaro region, Northern Tanzania: a descriptive cross-sectional study. BMJ Open 2021;11:e046841. doi:10.1136/ bmjopen-2020-046841

- Prepublication history for this paper is available online. To view these files, please visit the journal online (http://dx.doi. org/10.1136/bmjopen-2020046841).

Received 12 November 2020 Accepted 21 September 2021

\section{Check for updates}

(c) Author(s) (or their employer(s)) 2021. Re-use permitted under CC BY-NC. No commercial re-use. See rights and permissions. Published by BMJ.

${ }^{1}$ Department of Community Health, Institute of Public Health, Kilimanjaro Christian Medical University College, Kilimanjaro, Tanzania

${ }^{2}$ Department of Epidemiology and Biostatistics, Institute of Public Health, Kilimanjaro Christian Medical University College, Kilimanjaro, Tanzania ${ }^{3}$ School of Mathematics, Statistics, and Computer Science, University of KwaZuluNatal—Pietermaritzburg Campus, Pietermaritzburg, KwaZulu-Natal, South Africa

Correspondence to Dr Julius Lucas Mwimo; juliusmwimo@gmail.com

\section{ABSTRACT}

Introduction Diabetes mellitus is one of the most common non-communicable diseases and is the fifth leading cause of death in most developing countries. Regular physical activity (PA) is strongly recommended for individuals with diabetes for its beneficial effects in improving blood glucose control and insulin sensitivity, prevention and reduction of morbidities and complications and its cardiovascular benefits.

Objective To assess the knowledge, attitude and practices of PA among patients with diabetes in the Kilimanjaro region, Northern Tanzania.

Research design and methods A cross-sectional study was conducted from June to September 2020 among 315 patients with diabetes aged 18 years and above receiving care from diabetic clinics in the Kilimanjaro region, Northern Tanzania. A systematic random sampling technique was used to select study participants who were interviewed using a modified version of the WHO-STEPS Survey for non-communicable diseases. Data were analysed using SPSS V.20. Categorical variables were summarised using frequencies and percentages, and continuous variables using means and SDs. The $\mathrm{X}^{2}$ test was used to compare the proportion of PA across participant characteristics. Results The vast majority (94.3\%) of the participants were physically active, and from our findings, most of it was contributed by work (70\%) and transport-related (20\%) activities. Participants had high levels of knowledge (98.4\%) and positive attitudes (95.6\%) towards PA. These were mainly contributed by a healthcare provider or doctors' advice (96\%) on PA benefits to patients with diabetes. There was a strong statistical association $(p<0.001)$ between knowledge and attitude towards PA with PA practice. Conclusion The vast majority of the participants were physically active. High levels of PA were associated with a high level of knowledge and positive attitudes towards PA. Healthcare provider or doctors' advice in diabetic clinics is essential in promoting PA practice in this population and in diabetes management.

\section{BACKGROUND}

Diabetes is a serious chronic disease that occurs when the pancreas does not produce

\section{Strengths and limitations of this study}

- This study provides evidence for good knowledge, positive attitudes and sufficient physical activity practices in this population.

- This study potentially helps further the research in physical activity among people with diabetes.

- Self-reported measures could have overestimated the respondents' physical activity levels, as demonstrated in this study.

- Inability to assess the temporal relationship, since it is a cross-sectional study.

- Since it was a hospital-based study, it may have affected the generalisability of this study's findings.

enough insulin or when the body cannot effectively use the insulin it produces. ${ }^{1}$ The number of people with diabetes is steadily rising, with the $\mathrm{WHO}$ estimating that $6 \%$ of the world's population has diabetes, four times the number in $1980 .{ }^{1}$ The greatest rise is in low-income and middle-income countries. Without interventions to halt this increase, there will be at least 629 million people living with diabetes by $2045 .^{2}$ Tanzania is not an exception to the ever-increasing prevalence of diabetes. A 2012 Tanzanian national survey estimated diabetes prevalence at $9.1 \%$ among adults aged 25-64 years, a significant increase of $4 \%$ compared with a study conducted in two regions of Tanzania in the year 2000, which showed a prevalence of $5 \%$ among adults aged $>15$ years. ${ }^{34}$ Also, the International Diabetic Federation showed a total of 897000 prevalent cases of diabetes in adults aged $20-79$ years in 2017 , with a prevalence of $3.6 \%$ in Tanzania. ${ }^{5}$

Weight control is key to the control of diabetes and the prevention of related negative consequences. Regular and adequate 
physical activity (PA) levels in adults reduce the risk of hypertension, coronary heart disease, stroke, diabetes, breast and colon cancer, depression, and the risk of falls, improving bone and functional health. ${ }^{6} \mathrm{PA}$ is also a key determinant of energy expenditure and thus fundamental to energy balance and body weight control. ${ }^{7}$ Several studies show PA is protective against diabetes and related complications such as diabetic neuropathy, retinopathy, cardiovascular disease, mortality, stroke, hypertension, cancers (colon, breast), and depression; enhances skeletal muscle mass and drop in blood glucose; and contributes to weight loss and regulation of blood pressure..$^{8-11}$

PA is also crucial among patients with diabetes because it has been associated with improved genomic stability, reduction in mortality rate and effective in lowering the susceptibility to oxidative DNA damage and the lipid peroxidation levels. ${ }^{12-14}$ Yet, the practice of PA is still low among patients with diabetes in different countries across the globe. For instance, the proportion in North America ranged from $32.8 \%$ in the USA to $39.5 \%$ in Canada. ${ }^{15}$ In Asian countries, it ranged from $10 \%$ in Kuwait to $28 \%$ in Nepal, ${ }^{16-18}$ while in Africa, it ranged from $27.4 \%$ in Nigeria to $81 \%$ in Senegal. ${ }^{11}{ }^{19-21}$ It is reported that the high proportion of PA in Senegal has been highly motivated by doctors' advice on PA. PA practice in East African countries is between $31.4 \%$ in Rwanda and $41 \%$ in Kenya ${ }^{21} 22$ compared with $33 \%$ in Tanzania. ${ }^{23}$ These findings indicate significant variations in the practice of PA among patients with diabetes between and within countries.

Sufficient knowledge and good attitude towards PAs are crucial for diabetes management. Limited knowledge of the duration and type of PA has been associated with poor adherence to PA among patients with diabetes. ${ }^{202425}$ Also, a negative attitude towards PA has no significant advantage in managing diabetes and is associated with poor adherence to PA among patients with type 2 diabetes. ${ }^{19} 26$

In Tanzania, studies have shown that sufficient knowledge of PA in diabetes management is very minimal, ${ }^{27}$ which contributes to the high rate of physical inactivity among patients with diabetes in the country. ${ }^{323}$ Nationally and regionally, there has been very little literature addressing the issue of PA among patients with diabetes, whereby the last similar study was conducted in the years 1996 and 1997 in Dar es Salaam and Kilimanjaro regions. ${ }^{3}$ Thus, this study will determine knowledge, attitude and practice of PA among patients with diabetes in the Kilimanjaro region.

\section{METHODS}

\section{Study design and setting}

We carried out a cross-sectional study from August to September 2020 among patients with diabetes attending two diabetic clinics in the Kilimanjaro region, Northern Tanzania. Kilimanjaro region has 7 administrative districts, 20 hospitals, 41 health centres and 335 dispensaries. The health facilities are owned by either the government, religious or private sectors. There are five diabetic clinics in the region, namely Kilimanjaro Christian Medical Centre (KCMC) Referral Hospital, Mawenzi Regional Hospital, Kilema, Rombo and Kibosho District Hospitals. Data collection was conducted in the KCMC Referral Hospital and Mawenzi Regional Hospital due to the high volume of patients with diabetes relative to other facilities in the region. KCMC is a zonal referral hospital serving over 15 million people in Northern Tanzania. Mawenzi Hospital is the regional hospital for the Kilimanjaro region serving around 1.7 million people.

\section{Study population, sample size and sampling}

The study population were patients with type 2 diabetes aged 18 years and above attending diabetic clinics in the Kilimanjaro region. We used a single proportion formula to estimate the minimum required sample size given as $\left[\mathrm{N}=(\mathrm{Za} / 2)^{2} \times \mathrm{p}(1-\mathrm{p}) / \mathrm{e}^{2}\right]$, where $N$ is the minimum required sample size, and $p$ is the estimated proportion of PA among patients with diabetes $(27.5 \%)$ based on a study conducted in Nigeria. ${ }^{19}$ Furthermore, $e$ is the margin of error or precision $(5 \%)$, and $Z$ is the standard normal value (1.96) corresponding to a $95 \%$ CI. After adding a $15 \%$ proportion of non-response, the estimated sample size was 353. A systematic random sampling technique was used to select study participants until the desired number was reached.

\section{Data collection methods and procedures}

Trained doctor of medicine students at the Kilimanjaro Christian Medical University College collected data using a modified version of the WHO-STEPS questionnaire for non-communicable diseases (NCDs). ${ }^{28}$ The WHOSTEPS questionnaire for NCDs is a tool that measures risk factors for chronic NCDs such as hypertension, diabetes, etc. The questionnaire was designed in English and then translated by the study team and administered in Swahili, the local language in Tanzania. The team members translated one question after another and where there was a disagreement on the Swahili translation, the supervisor was consulted; and if consensus was not reached, other experts within the college environment were consulted. The tool contained information on behavioural characteristics (smoking, alcohol intake and diet), PA practices, history of raised blood pressure, history of raised cholesterol, and physical measurements like blood pressure, weight and height. ${ }^{29}$ The tool was modified, that is, removed questions about diabetes because the study was among patients with diabetes and added questions on knowledge and attitudes towards PA. A total of 12 questions assessed the knowledge and 10 questions assessed the attitude towards PA. These questions on knowledge and attitude were adapted from a study in Nigeria. ${ }^{30}$

Participants were provided with clear information about the study purpose, benefits for participation, anticipated harm and what was expected of their involvement. After addressing all participant questions, informed consent was administered. Those who refused to participate 
continued with routine care. All consenting participants were interviewed by trained medical students in a quiet and secure room or a place within the clinic to ensure confidentiality. Interviews took approximately 20-30 min to complete and thereafter the participants continued with routine care. Immediately after data collection, the researchers assessed the patterns and completeness of the collected data.

\section{Study variables}

The outcome variables in this study were knowledge, attitude and PA practices. Knowledge of PA was assessed using 12 questions with Yes (1) and No (0) responses. ${ }^{30}$ Knowledge was scored by summing the scores of all questions of the domain. The scores were then converted to percentages, and a higher percentage score $(\geq 75 \%)$ indicated good PA knowledge.

The attitude towards PA was measured using 10 items on a 3-point scale, that is, disagree, neutral and agree. ${ }^{30}$ Items $1-3,9$ and 10 were reverse-coded because of the negative meanings of the items. Then, attitude towards PA was scored by summing all the scores of all items with a higher score $(\geq 75 \%)$, suggesting a favourable attitude towards PA.

PA practice was measured using questions from the WHO Global Physical Activity Questionnaire. ${ }^{31}$ The PA practice questions were divided into three sections: workrelated PA, transport-related PA (related to walking or cycling) and leisure-related PA. Time spent on all PA types was summed to obtain each PA type's time spent per week. Frequency, duration and intensity for each PA type were coded into metabolic equivalent (MET) tables. One MET is defined as the energy expenditure while sitting quietly for 1 hour, which for the average adult is approximately $3.5 \mathrm{~mL}$ of oxygen $/ \mathrm{kg}$ body weight/min with MET values obtained from the Compendium of PA. ${ }^{32}$

Vigorous-intensity work-related PA was assigned a value of 8.0 METs while moderate-intensity work-related PA was assigned a value of 4.0 METs. Transport-related PA was assigned a value of 4.0 METs. Vigorous-intensity leisurerelated PA was assigned a value of 8.0 METs, and moderateintensity leisure-related PA was assigned a value of 4.0 METs. ${ }^{33}$ The total MET per week for all PAs was calculated by multiplying the duration (minutes) of activity per week by its corresponding METs and summed for each PA type. Sufficient MET was defined as $\geq 600$ METs per week. ${ }^{31}$ Other study variables included age $(<40,40-59$, $60+$ years), sex (male, female), marital status (married, not married), education level (primary, secondary, tertiary), employment status (employed, self-employed, unemployed), body mass index (BMI) (normal weight, overweight, obese), and behavioural characteristics such as smoking, alcohol consumption and diet.

\section{Data analysis}

We performed data analysis using SPSS V.20 software. Categorical variables were summarised using frequencies and percentages, and continuous variables using
Table 1 Participants' background characteristics ( $N=315)$

\begin{tabular}{|c|c|c|}
\hline Variable & Frequency & Percentage \\
\hline \multicolumn{3}{|l|}{ Age in years } \\
\hline$<40$ & 20 & 6.3 \\
\hline $40-59$ & 146 & 46.3 \\
\hline $60+$ & 149 & 47.3 \\
\hline Mean (SD) & $58.6(10.8)$ & \\
\hline \multicolumn{3}{|l|}{ Sex } \\
\hline Male & 131 & 41.6 \\
\hline Female & 184 & 58.4 \\
\hline \multicolumn{3}{|l|}{ Education level } \\
\hline Primary & 170 & 54.0 \\
\hline Secondary & 93 & 29.5 \\
\hline Tertiary & 52 & 16.5 \\
\hline \multicolumn{3}{|l|}{ Marital status } \\
\hline Married & 238 & 75.6 \\
\hline Not married & 77 & 24.4 \\
\hline \multicolumn{3}{|l|}{ Employment status } \\
\hline Employed & 74 & 23.5 \\
\hline Self-employed & 124 & 39.4 \\
\hline Unemployed & 117 & 37.1 \\
\hline \multicolumn{3}{|l|}{ BMI } \\
\hline Normal weight & 67 & 21.3 \\
\hline Overweight & 186 & 59.0 \\
\hline Obese & 62 & 19.7 \\
\hline
\end{tabular}

BMI, body mass index.

means and SDs. The $\mathrm{X}^{2}$ test was used to compare the proportion of PA across participant characteristics, and a $p$ value of $<0.05$ was considered a statistically significant association.

\section{Patient and public involvement}

Patients or the public were not involved in the design, or conduct, or reporting, or dissemination plans of our research.

\section{RESULTS}

\section{Participants' demographic characteristics}

A total of 353 patients with diabetes met the inclusion criteria and were invited to participate in the study. Of these, 315 consented to participate in making a response rate of $89 \%$ since the rest $(11 \%)$ were not comfortable completing the questionnaire. The mean age of 315 respondents was $58.62 \pm 10.8$ years, and almost half $(47.3 \%)$ were $>60$ years. Women accounted for $58.4 \%$ of all study participants, $54 \%$ had primary education level and three-quarters $(75.6 \%)$ were married (table 1$)$.

\section{Behavioural characteristics}

Among all respondents, only $3 \%$ were current smokers, and $54.9 \%$ ever consumed alcohol. Of those who ever 


\begin{tabular}{|c|c|c|}
\hline Variable & Frequency & Percentage \\
\hline \multicolumn{3}{|c|}{ Currently smoking } \\
\hline Yes & 9 & 2.9 \\
\hline No & 306 & 97.1 \\
\hline \multicolumn{3}{|c|}{ Ever smoked in the past $(n=306)^{*}$} \\
\hline Yes & 40 & 13.1 \\
\hline No & 266 & 86.9 \\
\hline \multicolumn{3}{|c|}{ Ever consumed alcohol } \\
\hline Yes & 173 & 54.9 \\
\hline No & 142 & 45.1 \\
\hline
\end{tabular}

Consumed alcohol within

the past 12 months $(n=173)^{*}$

\begin{tabular}{lrl}
\hline Yes & 43 & 24.9 \\
\hline No & 130 & 75.1 \\
\hline $\begin{array}{l}\text { Stopped drinking due to } \\
\text { health reasons ( } \mathrm{n}=173)^{*}\end{array}$ & \\
\hline $\begin{array}{l}\text { Yes } \\
\text { No }\end{array}$ & 127 & 73.4 \\
\hline $\begin{array}{l}\text { Add salt when eating } \\
\text { Frequently }\end{array}$ & 46 & 26.6 \\
\hline $\begin{array}{l}\text { Rarely/never } \\
\text { Add salt when cooking }\end{array}$ & 64 & 20.3 \\
\hline $\begin{array}{l}\text { Frequently } \\
\text { Rarely/never }\end{array}$ & 112 & 79.7 \\
\hline $\begin{array}{l}\text { Consume processed food } \\
\text { high in salt }\end{array}$ & 203 & 35.6 \\
\hline $\begin{array}{l}\text { Frequently } \\
\text { Rarely/never }\end{array}$ & 64.6 \\
\hline
\end{tabular}

*Variables containing missing values.

consumed alcohol $(\mathrm{n}=173)$, a quarter $(24.9 \%)$ consumed in the past year, and $73.4 \%$ stopped drinking due to health reasons. About $20 \%$ of all add salt when eating, $35.6 \%$ when cooking and $16.8 \%$ consume processed food high in salt (table 2).

\section{Knowledge of PAs}

The vast majority $(95.6 \%)$ of participants reported knowing that PA is any form of bodily movement, including dancing and going up and down the stairs $(99.7 \%)$, safe PA in diabetes increased breath moderately $(91.7 \%)$ and would make them sweat mildly $(93.7 \%)$. Also, nearly all (99\%) reported that PA included leisure walking in the neighbourhood (99\%), riding a mobile or stationary bicycle $(97.8 \%)$, PA could be incorporated into leisure time $(96.8 \%)$ and PA includes recreational activities $(95.2 \%)$. Overall, $98.4 \%$ of all participants had good knowledge of PA (table 3).

\section{Attitude towards PA}

The majority of participants were always concerned about their PA level (63.3\%), considered engagement in regular PA
Table 3 Knowledge of physical activities (PAs) (N=315)

\begin{tabular}{|c|c|c|}
\hline Variable & Frequency* & Percentage* $^{*}$ \\
\hline \multicolumn{3}{|l|}{ Knowledge of PA } \\
\hline $\begin{array}{l}\text { PA is any form of bodily } \\
\text { movement }\end{array}$ & 301 & 95.6 \\
\hline $\begin{array}{l}\text { Safe PA increases breathing rate } \\
\text { moderately }\end{array}$ & 289 & 91.7 \\
\hline $\begin{array}{l}\text { Safe PA will make you sweat } \\
\text { mildly }\end{array}$ & 295 & 93.7 \\
\hline $\begin{array}{l}\text { PA includes housework and } \\
\text { working in the garden }\end{array}$ & 314 & 99.7 \\
\hline $\begin{array}{l}\text { PA includes dancing or going up } \\
\text { and down the stairs }\end{array}$ & 314 & 99.7 \\
\hline $\begin{array}{l}\text { PA includes leisure walking in } \\
\text { the neighbourhood }\end{array}$ & 312 & 99.0 \\
\hline $\begin{array}{l}\text { PA includes riding a mobile or } \\
\text { stationary bicycle }\end{array}$ & 308 & 97.8 \\
\hline PA benefits overall health & 315 & 100 \\
\hline $\begin{array}{l}\text { PA does not have to be } \\
\text { expensive }\end{array}$ & 315 & 100 \\
\hline PA does not have to be hard & 313 & 99.4 \\
\hline $\begin{array}{l}\text { PA can be incorporated into } \\
\text { leisure time }\end{array}$ & 305 & 96.8 \\
\hline $\begin{array}{l}\text { PA includes recreational } \\
\text { activities }\end{array}$ & 300 & 95.2 \\
\hline \multicolumn{3}{|l|}{ Overall knowledge of PA } \\
\hline Good & 310 & 98.4 \\
\hline Poor & 5 & 1.6 \\
\hline
\end{tabular}

*Frequencies and percentages among those who answered 'Yes'.

as not being fanatical $(68.9 \%)$ and extra PA outside normal daily activities is necessary for diabetes (72.7). Furthermore, PA behaviour made respondents feel well $(88.6 \%)$, derive a lot of pleasure in PA practice as patients with diabetes $(83.8 \%)$ and believed the practice would be beneficial to them $(99.4 \%)$. The majority $(97.1 \%)$ also believed that PA was not risky in diabetes and that regular PA reduced blood sugar (99.4\%). Nearly all participants (99\%) would encourage regular PA behaviour in individuals with diabetes. Overall, the vast majority $(95.6 \%)$ of all study participants in this study had positive attitudes towards PA (table 4).

\section{PA practices among patients with diabetes}

Overall, $94.3 \%$ of respondents had sufficient levels of PA ( $\geq 600$ METs). Work-related activities were the largest contributor $(70 \%)$ to the total $\mathrm{PA}$, specifically the moderate-intensity work-related activities, which accounted for $86 \%$ of all work-related PAs. Walking for travel was the second major contributor (20\%) to the total PA in this study (table 5).

\section{PA by participant characteristics}

There were statistically significant differences in the proportions of PA by marital status, employment, 
Table 4 Attitude towards physical activity (PA) (N=315)

\begin{tabular}{|c|c|c|c|}
\hline Variable & Disagree $\mathrm{n}(\%)$ & Neutral n (\%) & Agree n (\%) \\
\hline \multicolumn{4}{|l|}{ Attitude towards PA } \\
\hline Always concerned about PA level & $64(20.3)$ & $51(16.2)$ & $200(63.3)$ \\
\hline Extra PA outside normal daily activities is unnecessary in diabetes & $229(72.7)$ & $27(8.6)$ & $59(18.7)$ \\
\hline Need to be physically active enough to reduce my blood sugar & $8(2.5)$ & $2(0.6)$ & $305(96.8)$ \\
\hline Would encourage regular PA behaviour in individuals with diabetes & $1(0.3)$ & $2(0.6)$ & $312(99)$ \\
\hline I derive pleasure in PA behaviour as a patient with diabetes & $12(3.8)$ & $39(12.4)$ & $264(83.8)$ \\
\hline I believe PA behaviour will be beneficial to me as a patient with diabetes & $2(0.6)$ & $0(0)$ & $313(99.4)$ \\
\hline $\mathrm{PA}$ is risky in diabetes & $306(97.1)$ & $8(2.5)$ & $1(0.3)$ \\
\hline Regular PA does not reduce blood sugar & $313(99.4)$ & $1(0.3)$ & $1(0.3)$ \\
\hline
\end{tabular}

Table 5 Participants' different levels of PA ( $N=315)$

\begin{tabular}{|c|c|c|}
\hline Variable & Frequency & Percentage \\
\hline \multicolumn{3}{|l|}{ Work related } \\
\hline \multicolumn{3}{|c|}{ Vigorous intensity } \\
\hline Sufficient & 29 & 9.2 \\
\hline Insufficient & 286 & 90.8 \\
\hline \multicolumn{3}{|c|}{ Moderate intensity } \\
\hline Sufficient & 235 & 74.6 \\
\hline Insufficient & 80 & 25.4 \\
\hline \multicolumn{3}{|c|}{ Total work related } \\
\hline Sufficient & 236 & 74.9 \\
\hline Insufficient & 79 & 25.1 \\
\hline \multicolumn{3}{|c|}{ Transport related } \\
\hline Sufficient & 175 & 55.6 \\
\hline Insufficient & 140 & 44.4 \\
\hline \multicolumn{3}{|c|}{ Leisure related } \\
\hline \multicolumn{3}{|c|}{ Vigorous intensity } \\
\hline Sufficient & 15 & 4.8 \\
\hline Insufficient & 300 & 95.2 \\
\hline \multicolumn{3}{|c|}{ Moderate intensity } \\
\hline Sufficient & 62 & 19.7 \\
\hline Insufficient & 253 & 80.3 \\
\hline \multicolumn{3}{|c|}{ Total leisure-related PA } \\
\hline Sufficient & 66 & 21 \\
\hline Insufficient & 249 & 79 \\
\hline \multicolumn{3}{|c|}{ Overall PA level } \\
\hline Sufficient & 297 & 94.3 \\
\hline Insufficient & 18 & 5.7 \\
\hline
\end{tabular}

Sufficient levels of PA are equivalent to $\geq 600$ METs. METs, metabolic equivalents; PA, physical activity. knowledge and attitudes towards PA, and being hypertensive (table 6). A higher proportion of sufficient PA was among patients with diabetes who were married $(95.8 \%)$, employed $(100 \%)$, self-employed $(98.4 \%)$, with good knowledge $(94.8 \%)$ and positive attitudes $(96.3 \%)$ towards PA. Most (98.4\%) of the patients without hypertension had sufficient PA compared with among those $(91.6 \%)$ with self-reported hypertension (table 6$)$.

\section{DISCUSSION}

The study aimed to assess knowledge, attitude and practices of PAs among patients with diabetes in the Kilimanjaro region, Northern Tanzania. The findings show that $98.4 \%$ of all participants had good knowledge, and $95.6 \%$ had positive attitudes towards PA. The vast majority $(94.3 \%)$ of participants had sufficient ( $\geq 600$ METs) PA.

The patients with diabetes in this study met the WHO recommendations for sufficient ( $\geq 600$ METs) PA, which is way higher than that observed in various sub-Saharan African countries, with estimates ranging from $27.4 \%$ in Nigeria to 33\% in Dar es Salaam, Tanzania. 112023 The higher proportion of PA in our study might be explained by a high level of good knowledge, positive attitudes towards PA and employment status. As also reported in Senegal, doctors' advice on the importance of PA is critical to diabetes management. On the other hand, findings from a population-based crosssectional study in Mwanza, Northwestern Tanzania revealed that $96 \%$ of adults (aged 15 years and older) had sufficient $\mathrm{PA}^{34}$ The authors indicated that the high prevalence of PA was explained by the fact that the population sampled were: working class, residing in a rural area and involved in farming activities. $^{34}$

Participation in PA is likely to differ depending on the study population and context-specific factors. Workrelated moderate-intensity activities accounted for $57.5 \%$ of the total PA in this study. These activities included 
Table 6 PA by participant characteristics $(\mathrm{N}=315)$

\begin{tabular}{cccc}
\hline Variable & $\begin{array}{l}\text { Insufficient PA } \\
\text { n (\%) }\end{array}$ & $\begin{array}{l}\text { Sufficient PA } \\
\mathbf{n}(\%)\end{array}$ & P value \\
\hline Gender & & & 0.47 \\
Male & $9(6.9)$ & $122(93.1)$ &
\end{tabular}

\begin{tabular}{|c|c|c|c|}
\hline Female & $9(4.9)$ & $175(95.1)$ & \\
\hline Marital status & & & 0.042 \\
\hline Married & $10(4.2)$ & $228(95.8)$ & \\
\hline Unmarried & $8(10.4)$ & $69(89.6)$ & \\
\hline BMI & & & 0.9 \\
\hline Normal weight & $4(6)$ & $63(94)$ & \\
\hline Overweight & $10(5.4)$ & $176(94.6)$ & \\
\hline Obese & $4(6.5)$ & $58(93.5)$ & \\
\hline Employment status & & & $<0.001$ \\
\hline Employed & $0(0)$ & $74(100)$ & \\
\hline Self-employed & $2(1.6)$ & $122(98.4)$ & \\
\hline Unemployed & $16(13.7)$ & 101 (86.3) & \\
\hline Knowledge of PA & & & $<0.001$ \\
\hline Good & $16(5.2)$ & $294(94.8)$ & \\
\hline Poor & $2(40)$ & $3(60)$ & \\
\hline Attitude towards PA & & & $<0.001$ \\
\hline Positive & $11(3.7)$ & 290 (96.3) & \\
\hline Negative & $7(50)$ & $7(50)$ & \\
\hline Education level & & & 0.372 \\
\hline Primary & $12(7)$ & $158(93)$ & \\
\hline Secondary & $5(5.4)$ & $88(94.6)$ & \\
\hline Tertiary & $1(2)$ & $51(98)$ & \\
\hline Have hypertension & & & 0.012 \\
\hline Yes & $16(8.4)$ & $174(91.6)$ & \\
\hline No & $2(1.6)$ & $123(98.4)$ & \\
\hline
\end{tabular}

Sufficient levels of PA are equivalent to $\geq 600$ METs.

BMI, body mass index; METs, metabolic equivalents; PA, physical activity.

household chores and agriculture-related activities. The results are similar to those found in Rwanda. ${ }^{21}$ In this study, $62.9 \%$ of all participants were employed and engaged in agricultural activities. Leisure activity participation was lower $(10 \%)$ than other activities. Again, our results are consistent with a study done in Nepal and Rwanda. ${ }^{1821}$ This might be because participants thought it was enough to engage in agricultural activities.

The knowledge and attitudes towards PA were significantly associated with PA practice, as also reported in other studies. ${ }^{18192133}$ The knowledge of PA in this study is high $(98.4 \%)$, as also reported in other studies. ${ }^{202425}$ Our findings are, however, very high compared with those reported elsewhere. ${ }^{22} 2633$ The regular counselling might have contributed to the high proportion of knowledge of PA among patients with diabetes in our study on the importance of maintaining healthy body weight or weight loss in managing diabetes and regular attendance to diabetic clinics. Such an intervention is crucial to encouraging patients with diabetes to engage in frequent PA for blood sugar, body weight control and diabetic control. ${ }^{20}$ Patients attending routine diabetic clinics should frequently and consistently be advised and reminded about the importance of PA in the management of diabetes.

The vast majority $(95.6 \%)$ of patients with diabetes in this study had a positive attitude towards PA, consistent with other studies. ${ }^{20} 33$ These results are contrary to a similar study in Nigeria, where $90 \%$ of the study participants had a negative attitude towards PA. ${ }^{19}$ The poor attitude reported in Nigeria can be attributed to inadequate health education on the importance of PA and reliance on drugs as the main treatment approach for the regulation of plasma blood glucose. ${ }^{19}$ The positive attitude towards PA is an integral part of diabetes treatment and can potentially translate to participation in PA. ${ }^{11}$ A positive attitude towards $\mathrm{PA}$ is likely to translate to participation in PA practice. ${ }^{35}$

\section{Strengths and limitations of the study}

Our findings provided evidence for good knowledge, positive attitudes and sufficient PA practices in this population. Also, the study potentially helps further the research on PA among people with diabetes. However, the study does have some shortcomings. First, self-reported measures could have overestimated the respondents' PA levels, as demonstrated in this study. MET values of some activities, which involve high breathing, have not been derived from actual oxygen consumption, hence increasing the risk of overestimation. In addition, higher proportion of PA knowledge, attitude and practice in this study might reflect limited applicability of the WHO-STEPS tool among patients with diabetes in this setting. As earlier indicated, work-related moderate-intensity activities accounted for nearly $60 \%$ of the total PA in this study. The 600 METs per day could be achieved by just walking from one point to another given the mountainous terrain of most parts of Kilimanjaro region. All these do not necessarily translate to adequate diabetes care or management. Second, some individuals might have incorrectly reported the information collected in minutes of PA due to the inherent difficulty of recalling the number of minutes spent in 1 week doing any activity. The study was hospital based which affects the generalisability of this study's findings. Finally, an inherent limitation of cross-sectional studies is the inability to assess the temporal relationship.

\section{Conclusion and recommendations}

The vast majority of patients with diabetes were physically active. High levels of PA were associated with a high level of knowledge and positive attitudes towards PA. Healthcare provider or doctors' advice in diabetic clinics is essential in promoting PA practice in this population and in diabetes management.

Contributors All authors made a substantial contribution to this study. JLM, SS, EM and IBM designed the study. JLM, SS and EM collected and analysed the data. IBM, CA and BJL commented on the manuscript. JLM drafted the manuscript and had the primary responsibility for the final content. All authors reviewed the drafts of this manuscript and approved the final version for submission. 
Funding The authors have not declared a specific grant for this research from any funding agency in the public, commercial or not-for-profit sectors.

Competing interests None declared.

Patient and public involvement Patients and/or the public were not involved in the design, or conduct, or reporting, or dissemination plans of this research.

Patient consent for publication Obtained.

Ethics approval The study was approved by the Kilimanjaro Christian Medical University College Research and Ethics Review Committee (KCMU-CRERC), with the ethical approval number being UG/085/2020. Permission to conduct the study was sought from the Kilimanjaro region medical officer (for Mawenzi Hospital) and the KCMC hospital director. Participants provided oral informed consent, and participation was voluntary. Participants were also informed that they were free to withdraw from the study anytime they felt so without affecting their care process. To protect the privacy and confidentiality of the participant information, we used unique identification numbers.

Provenance and peer review Not commissioned; externally peer reviewed. Data availability statement Data are available upon reasonable request.

Open access This is an open access article distributed in accordance with the Creative Commons Attribution Non Commercial (CC BY-NC 4.0) license, which permits others to distribute, remix, adapt, build upon this work non-commercially, and license their derivative works on different terms, provided the original work is properly cited, appropriate credit is given, any changes made indicated, and the use is non-commercial. See: http://creativecommons.org/licenses/by-nc/4.0/.

\section{ORCID iDs}

Julius Lucas Mwimo http://orcid.org/0000-0002-3824-8170

Beatrice J Leyaro http://orcid.org/0000-0002-8525-0281

Innocent B Mboya http://orcid.org/0000-0001-9861-5879

\section{REFERENCES}

1 Diabetes. Available: https://www.who.int/news-room/fact-sheets/ detail/diabetes [Accessed 10 Mar 2020].

2 WHO. Global report on diabetes. ISBN 2016;978:6-86 http://www. who.int/about/licensing/

3 Aspray T, Mugusi F, Rashid S. Rural and urban differences in diabetes prevalence in Tanzania: the role of obesity, physical inactivity and urban living. Trans $R$ Soc Trop Med Hyg 2000;94:637-44.

4 Mayige M, Kagaruki G. Tanzania steps survey report ministry of health and social nationalinstitute for medical in collaboration with world health 2013:1-154.

5 Ogurtsova K, da Rocha Fernandes JD, Huang Y, et al. IDF diabetes atlas: global estimates for the prevalence of diabetes for 2015 and 2040. Diabetes Res Clin Pract 2017;128:40-50.

6 WHO. Physical activity. Available: https://www.who.int/news-room/ fact-sheets/detail/physical-activity [Accessed 10 Mar 2020].

7 WHO. Global recommendations on physical activity for health, 2010.

8 Thomas N, Alder E, Leese GP. Barriers to physical activity in patients with diabetes. Postgrad Med J 2004;80:287-91.

9 Colberg SR, Sigal RJ, Fernhall B, et al. Exercise and type 2 diabetes: the American College of sports medicine and the American diabetes association: joint position statement. Diabetes Care 2010;33:e147-67.

10 Sluik D, Buijsse B, Muckelbauer R, et al. Physical activity and mortality in individuals with diabetes mellitus: a prospective study and meta-analysis. Arch Intern Med 2012;172:1285-95.

11 Djiby S, Demba D, Assane NM, et al. The knowledge, attitudes and practices of diabetics on physical activity at the mARC Sankale center of Dakar. OJIM 2018;08:33-41.

12 Arem H, Moore SC, Patel A, et al. Leisure time physical activity and mortality: a detailed pooled analysis of the dose-response relationship. JAMA Intern Med 2015;175:959-67.
13 Pittaluga M, Sgadari A, Dimauro I, et al. Physical exercise and redox balance in type 2 diabetics: effects of moderate training on biomarkers of oxidative stress and DNA damage evaluated through comet assay. Oxid Med Cell Longev 2015;2015:1-7.

14 Dimauro I, Sgura A, Pittaluga M, et al. Regular exercise participation improves genomic stability in diabetic patients: an exploratory study to analyse telomere length and DNA damage. Sci Rep 2017;7:1-12.

15 Joseph JJ, Echouffo-Tcheugui JB, Golden SH, et al. Physical activity, sedentary behaviors and the incidence of type 2 diabetes mellitus: the multi-ethnic study of atherosclerosis (MESA). BMJ Open Diab Res Care 2016;4:e000185-12.

16 Fattahi A, Barati M, Bashirian S. Physical activity and its related factors among type 2 diabetic patients in Hamadan. Iran J Diabetes Obes 2014;6:85-92.

17 Carballo M, Mohammad A, Maclean EC, et al. Knowledge, attitudes, behaviours and practices towards diabetes mellitus in Kuwait. East Mediterr Health J 2018;24:1098-102.

18 Kadariya S, Aro AR. Barriers and facilitators to physical activity among urban residents with diabetes in Nepal. PLoS One 2018;13:e0199329-21.

19 Awotidebe TO, Adedoyin RA, Afolabi MA, et al. Knowledge, attitude and practice of exercise for plasma blood glucose control among patients with type-2 diabetes. Diabetes Metab Syndr 2016;10:S1-6.

20 le RM, Walsh C, Reid M. Diabetes-related knowledge, attitude and practices (KAP) of adult patients with type 2 diabetes mellitus in the free state Province, South Africa. South African J Clin Nutr 2019;32:83-90.

21 Kabanda AM, Phillips JS. Physical activity among adults with diabetes mellitus in Rwanda. Af J Phys Health Edu Rec Dance 2011;17:239-47.

22 Lucy WA, Muthoni JOY, Ochieng OV. Physical activity practices among adults with diabetes : a clinical survey on management of diabetes mellitus at kenyatta national. African J Appl Hum Sci2009;1:22-30.

23 Kamuhabwa AR, Charles E. Predictors of poor glycemic control in type 2 diabetic patients attending public hospitals in Dar ES Salaam. Drug Healthc Patient Saf 2014;6:155-65.

24 Thungathurthi S, Thungathurthi S, Kumar V. Self care knowledge on diabetes among diabetic patients in Warangal Region. Int J Life Sci Pharma Res 2012;2:16-21.

25 Ranasinghe P, Pigera A, Ishara MH. Knowledge and perceptions about diet and physical activity among Sri Lankan adults with diabetes mellitus: a qualitative study health behavior, health promotion and society. BMC Public Health 2015;15:1-10.

26 Shilubane H, Netshikweta L, Ralineba T. Beliefs and practices of diabetic patients in Vhembe district of Limpopo Province. Afr J Prim Health Care Fam Med 2016;8:1-6.

27 Stanifer JW, Cleland CR, Makuka GJ. Prevalence, risk factors, and complications of diabetes in the Kilimanjaro Region : a populationbased study from Tanzania 2016;11:1-13.

28 WHO STEPS. WHO STEPS instrument for noncommunicable disease risk factor surveillance, 2020: 20-30.

29 WHO STEPS. Question-by-question guide, 2017: 1-16.

30 Maruf FA, Ojukwu CC, Akindele MO. Perception, knowledge, and attitude toward physical activity behaviour: implications for participation among individuals with essential hypertension. High Blood Press Cardiovasc Prev 2018;25:53-60.

31 Guide A. global physical activity questionnaire.

32 Ainsworth BE, Haskell WL, Whitt MC, et al. Compendium of physical activities: an update of activity codes and Met intensities. Med Sci Sports Exerc 2000;32:S498-516.

33 WHO. NCDs | Global physical activity surveillance, 2020. Available: https://www.who.int/ncds/surveillance/steps/GPAQ/en/ [Accessed 14 Oct 2020]

34 John B, Todd J, Mboya I, et al. Physical activity and associated factors from a cross-sectional survey among adults in northern Tanzania. BMC Public Health 2017;17:1-8.

35 Okonta HI, Ikombele JB, Ogunbanjo GA. Knowledge, attitude and practice regarding lifestyle modification in type 2 diabetic patients. Afr J Prim Health Care Fam Med 2014;6:2-7. 